\title{
ENERGY BALANCE AT THE SURFACE IN KING GEORGE ISLAND - PRELIMINARY RESULTS OF ETA PROJECT
}

\author{
http://dx.doi.org/10.4322/apa.2014.059
}

\section{Amauri P. de Oliveira ${ }^{1, *}$, Jacyra Soares ${ }^{1}$, Georgia Codato ${ }^{1}$, Admir Créso de Lima Targino², Caio Jorge Ruman ${ }^{1}$}

\begin{abstract}
'Grupo de Micrometeorologia, Departamento de Ciências Atmoféricas, Universidade de São Paulo - USP, Rua do Matão, 1226, CEP 05508-090, São Paulo, SP, Brazil

Engenharia Ambiental, Universidade Tecnológica Federal do Paraná - UTFPR, Av. dos Pioneiros, 3131 ,
\end{abstract} CEP 86036-370, Londrina, PR, Brazil

*email: apdolive@usp.br

\begin{abstract}
In this work the diurnal evolution of the energy balance at the surface is estimated for the King George Island, based on in situ observations of net radiation, soil heat flux and vertical profiles of wind speed, air temperature and specific humidity measured at the South Tower in the Brazilian Antarctic Station Comandante Ferraz. The turbulent fluxes were estimated by adjusting vertical profiles expressions based on the Monin-Obukhov Similarity Theory. The diurnal evolution of the energy balance components at the surface indicates, during this period, that the large input of energy causes large imbalance in the surface energy balance. The imbalanced term, estimated also for other periods, seems to be related mainly to the heterogeneity of the land use and topography.
\end{abstract}

Keywords: energy balance, sensible heat, latent heat and soil heat flux

\section{Introduction}

Quantifying interaction between surface and atmosphere through observation is one of the most challenging tasks ever. It evolves estimating exchange of energy, mass and momentum, simultaneously, in different places, facing heterogeneities inherent to the surface of the Earth at different meteorological scales. Among all ecosystems the one represented by Antarctica is most challenging given the extreme weather conditions prevailing during most of the time. These difficulties worsen in the case of the Brazilian Antarctic Station Comandante Ferraz because it is located on the shoreline region of the King George Island that is characterized by highly complex topography. Besides, the land cover is continuously changing by the temporal and spatial distribution of precipitation.

The main goal of the ETA ("Estudo da Turbulência na Antártica”- Antarctica Turbulence Study) project is to estimate the energy fluxes of sensible and latent heat at the surface at the Brazilian Antarctic Station Comandante Ferraz using slow and fast response sensors (Oliveira et al., 2012). In this work the diurnal evolution of the energy balance components are estimated using in situ observations of net radiation and soil heat flux. Hourly values of turbulent fluxes were estimated using low response sensors to provide vertical profiles of wind speed, air temperature and specific humidity (Figure 1). Universal non dimensional vertical gradients, provided by the Monin-Obukhov Similarity Theory, were adjusted, by linear fitting technique, to the observed vertical profiles, yielding turbulent fluxes of sensible and latent heat.

\section{Materials and Methods}

Energy balance at the surface can be expressed as:

$$
\mathrm{Rn}=\mathrm{G}-\mathrm{H}-\mathrm{LE}+\mathrm{I}
$$

Where $\mathrm{Rn}$ is the net radiation, $\mathrm{G}$ is the soil energy flux, $\mathrm{H}$ and LE are the turbulent energy fluxes of sensible and latent heat and $\mathrm{I}$ is the imbalanced term. The imbalanced term takes into account the energy fluxes that are not associated to local sources, systematic errors caused by observations

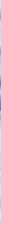



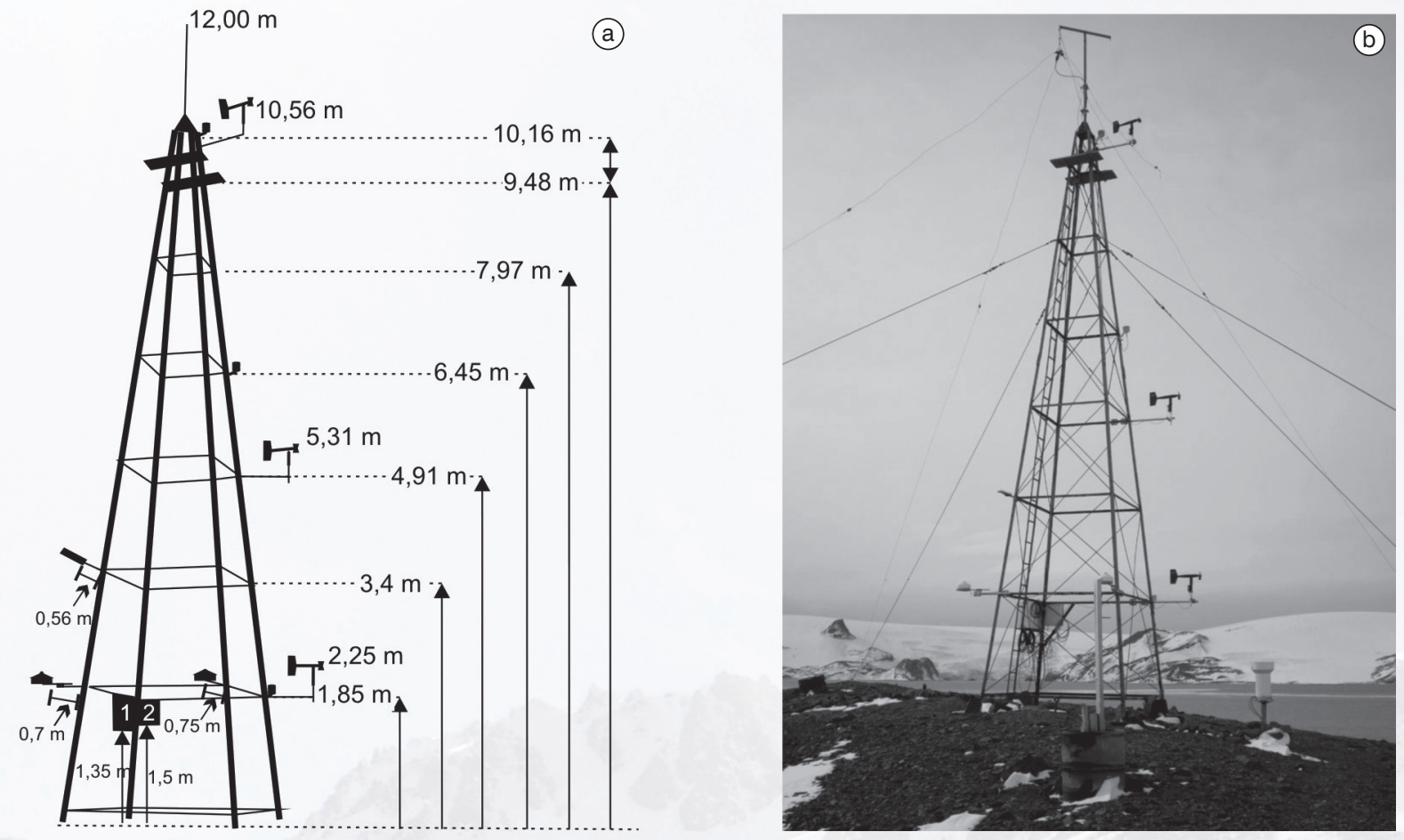

Figure 1. South tower of the Brazilian Antarctic Station Comandante Ferraz. (a) Schematic diagram and (b) photograph of the sensor set up in the tower.

and methodology limitations (Foken, 2008), and phase change of ice at the surface and frozen soil.

In this work all energy fluxes are positive when oriented upwards and vice versa. Here, the year day 52 (21 February 2012) is used as example of the energy balance, because the weather conditions are not significantly disturbed on this day.

\section{Results}

The soil temperature and the soil heat flux were obtained using, respectively, a soil temperature sensor and a soil heat flux plate set up at $5 \mathrm{~cm}$ below the surface (Figure 2).

The sensible and latent heat fluxes were estimated using vertical profiles of wind velocity (Figure $3 \mathrm{a}, \mathrm{b}$ ), air temperature (Figure 3c) and specific humidity Figure 3d). Details of the sensors used here can be found in Oliveira et al. (2012) and Codato et al. (2012).

According to Monin-Obukhov Similarity Theory, the mean vertical profiles of horizontal wind speed, potential temperature and specific humidity can be expressed in terms of non dimensional universal relations (Wyngaard, 2010). These functions depend on the stability of the surface layer and can be used to estimate the characteristic scales of velocity $\left(\mathrm{u}_{*}\right)$, temperature $\left(\theta_{*}\right)$ and specific humidity $\left(\mathrm{q}_{*}\right)$.

The net radiation was estimated using a net radiometer (Figure 4) installed at south tower of the EACF.

According to Monin-Obukhov Similarity Theory, the mean vertical profiles of horizontal wind speed, potential temperature and specific humidity can be expressed in terms of non dimensional universal relations (Wyngaard, 2010). These functions depend on the stability of the surface layer and can be used to estimate the characteristic scales of velocity $\left(\mathrm{u}_{*}\right)$, temperature $\left(\theta_{*}\right)$ and specific humidity $\left(\mathrm{q}_{*}\right)$.

The turbulent fluxes of sensible $(\mathrm{H})$ and latent heat (LE) (Figure $5 \mathrm{a}, \mathrm{b}$ ) are evaluated by the following expressions:

$$
\mathrm{H}=-\rho \mathrm{c}_{\mathrm{p}} \mathrm{u}_{*} \theta_{*} \mathrm{LE}=-\rho \mathrm{L} \mathrm{u}_{*} \mathrm{q}_{*}
$$



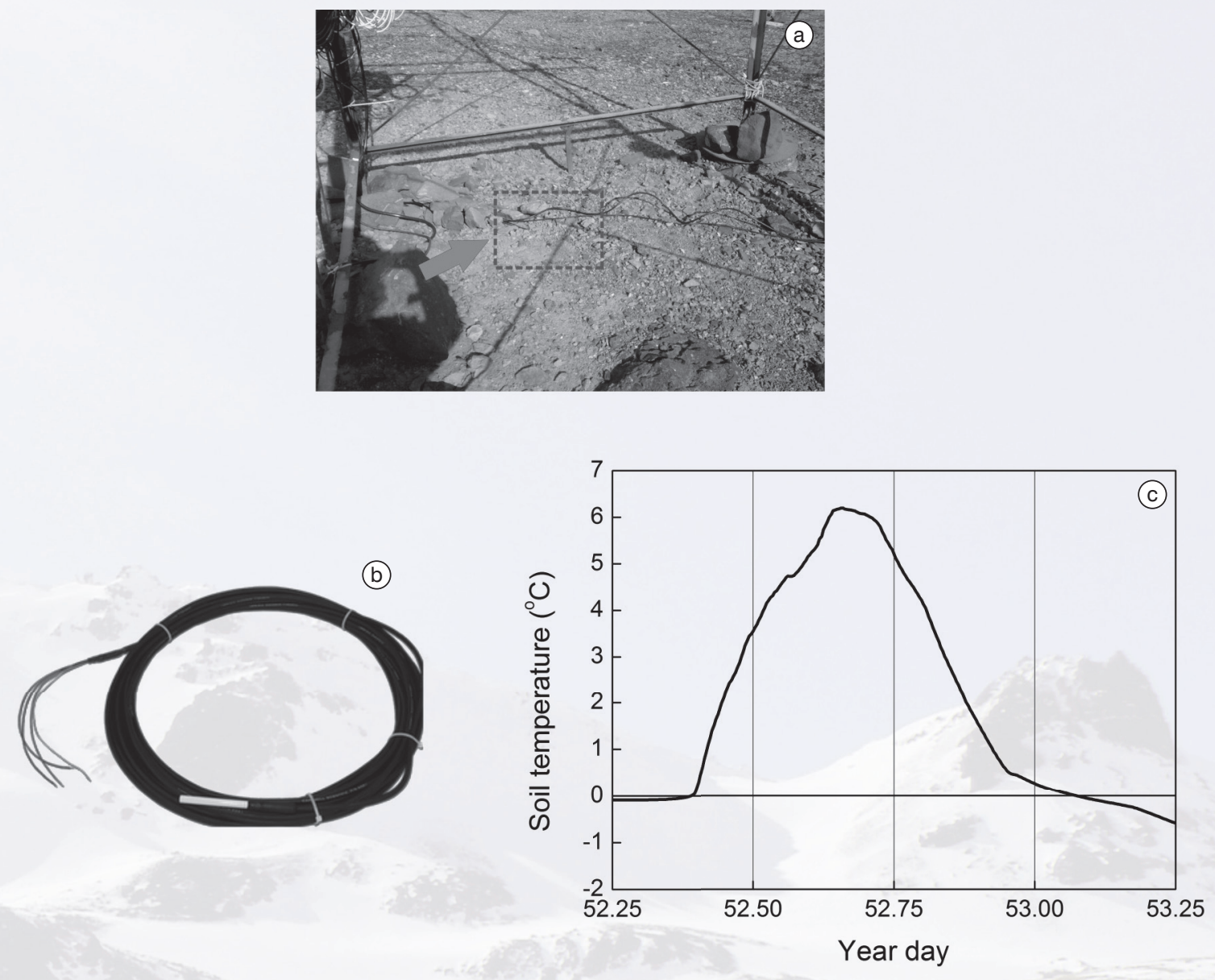

(b)

Figure 2. Soil heat flux. (a) Measurement local, (b) soil temperature sensor, (c) soil temperature $\left({ }^{\circ} \mathrm{C}\right.$ ) at $-5 \mathrm{~cm}$, (d) soil heat flux plate and (e) soil heat flux $\left(\mathrm{W} \mathrm{m}^{-2}\right)$ at $-5 \mathrm{~cm}$.

Where $\rho$ is de air density, $c_{\mathrm{P}}$ is the specific heat at constant pressure and $\mathrm{L}$ is the latent heat of vaporization.

\section{Discussion}

The major reason for the energy imbalance (Figure $5 c, d$ ) is that over heterogeneous landscape the turbulent exchange processes of larger scales cannot be captured by eddy covariance. Long wave and organized turbulence are not properly described because most of the eddy covariance algorithms do not consider the covariance when the signal is non stationary, so that $\mathrm{H}+\mathrm{LE}$ is underestimated. Besides, due to wind direction high variability the foot print has to be taken into consideration properly in order to reduce the error in $\mathrm{H}$ and LE measurements.
Another source of error is caused by phase difference between soil heat flux and surface temperature. Energy balance at the surface responds to the temperature and soil heat flux evolution in time at the surface, the later parameter is measured using heat plates at some depth so that there is a significant phase and amplitude difference between surface temperature and soil heat flux. Besides, soil heat plates always underestimate the soil heat flux amplitude due to the deflection of heat flux lines of the soil by introducing the plate with different thermal conductivity (Gao et al., 2010)

\section{Conclusion}

The diurnal evolution of the energy balance components at the surface indicates that in this particular period

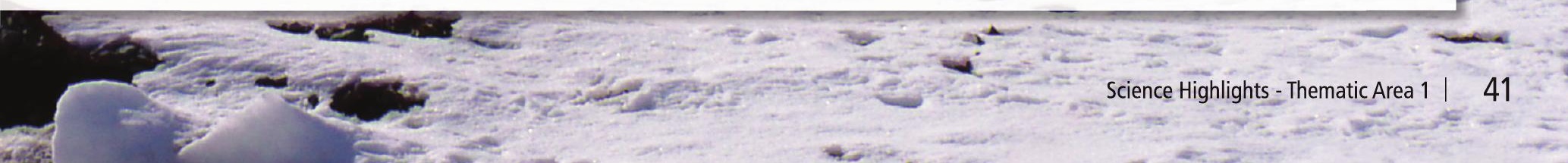



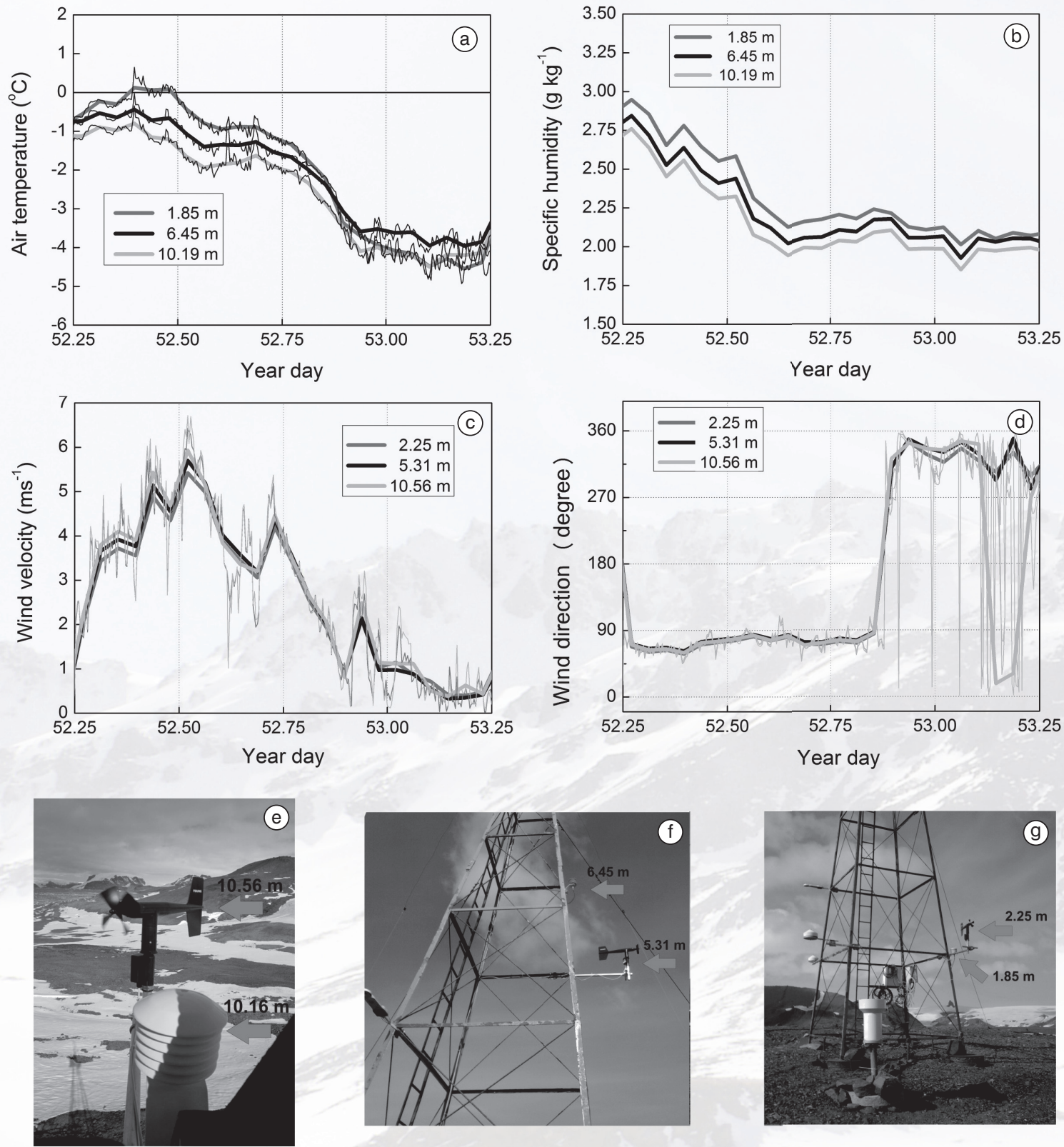

Figure 3. Diurnal variation, at 3 different levels, of (a) air temperature ( $\mathrm{C}$ ), (b) specific humidity $\left(\mathrm{g} \mathrm{kg}^{-1}\right)$, (c) wind velocity ( $\left.\mathrm{m} \mathrm{s}^{-1}\right)$ and (d) wind direction (degree). Photograph of the instruments (e) south tower upper level sensors, (f) middle level and (g) lower level.

(year day 52) there was a large input of energy, heating considerably the surface and the surface layer (Figure 5). There is a substantial imbalance that may be related to the methodology used to estimate the turbulent fluxes (indirect method), lack of representativeness of the soil heat flux and advection of heat associated mainly to the heterogeneity of the land use and topography of the region of the Brazilian Antarctic Station Comandante Ferraz. The next step is to compare the indirect method with the eddy correlation method. This will be possible when the sonic anemometer 
(a)
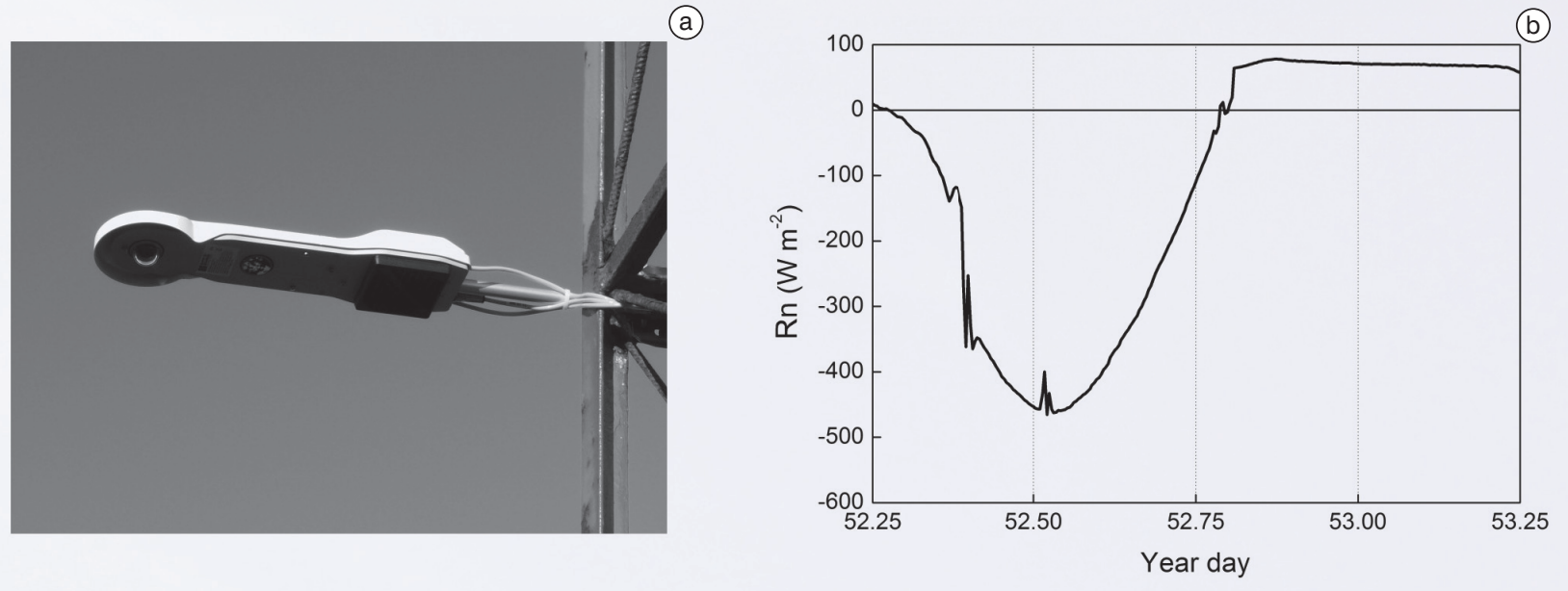

Figure 4. Net radiometer (a) at South tower and (b) diurnal evolution $\left(\mathrm{W} \mathrm{m}^{-2}\right)$.
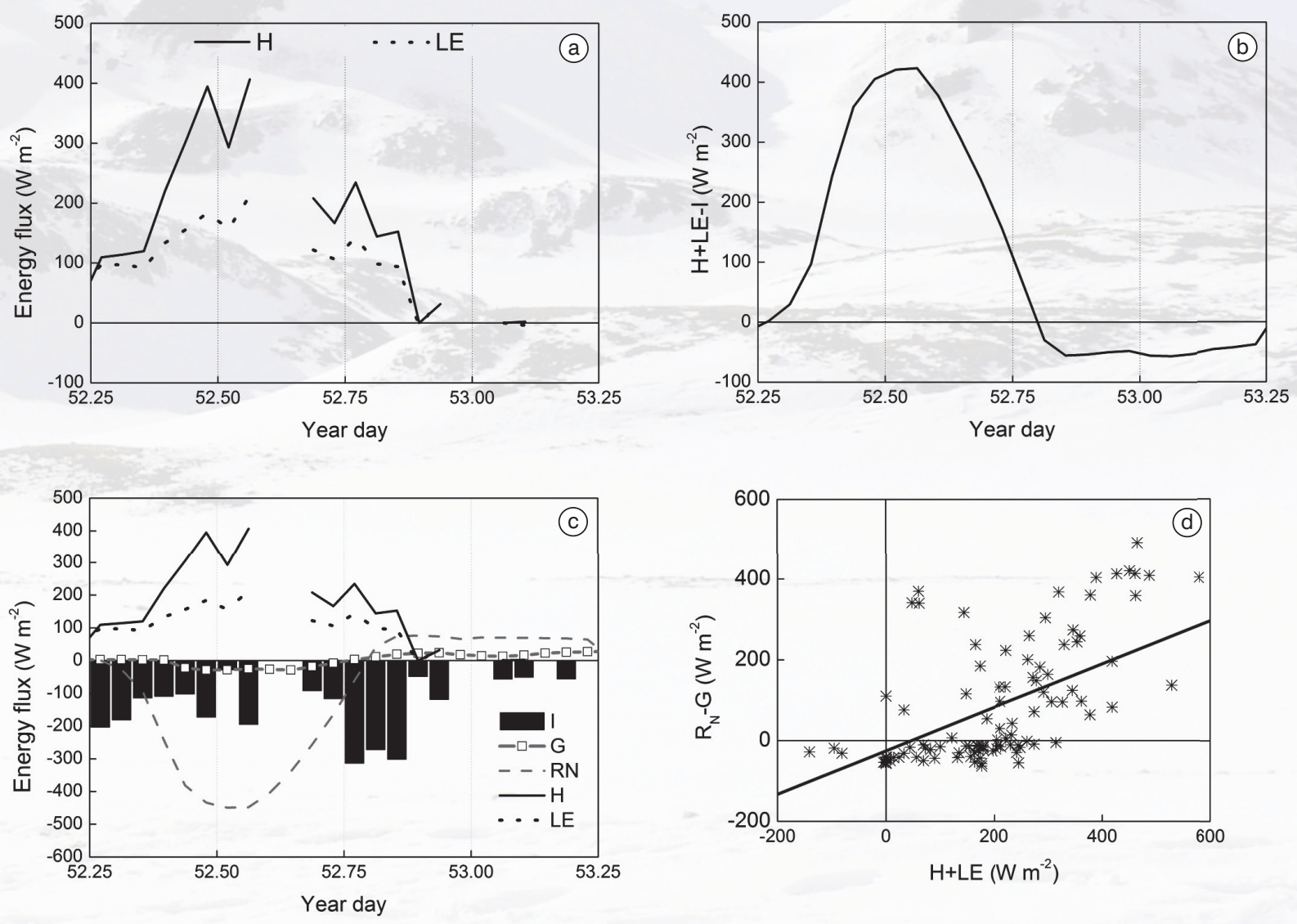

Figure 5. Diurnal evolution of (a) sensible and latent heat heat flux, (b) available energy flux, (c) energy balance components and (d) available energy versus turbulent fluxes (year days 51 to 55 of 2012)

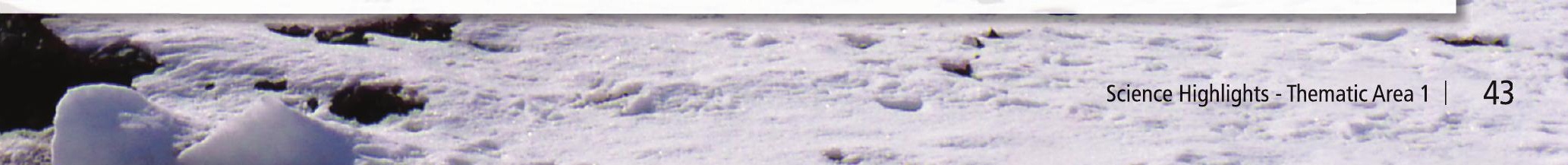


and infrared gas analyzer were setup in the South Tower as originally proposed in the ETA project.

\section{Acknowledgements}

The authors acknowledge the financial support provided by the Brazilian National Institute of Science and Technology -
Antarctic Environmental Research (INCT-APA, Portuguese acronym), the National Council for Scientific and Technological Development (CNPq, Portuguese acronym), process n574018/2008-5 and the Carlos Chagas Filho Research Foundation, (FAPERJ, Portuguese acronym), process No, FAPERJ-16/170.023/2008.

\section{References}

Codato, G.; Soares, J.; Oliveira, A.P.; Targino, A.C.L. \& Ruman, C.J. (2012). Observational campaigns of the ETA Project. Anais da 4ª Oficina de Trabalho do INCT-APA. 25 a 29 de junho de 2012. Rio de Janeiro, RJ.

Foken, T. (2008). The energy balance closure problem: An overview. Ecol. Appl., 18(6): 1351-1367.

Gao, Z.; Horton, R. \& Liu, H.P. (2010). Impact of wave phase difference between soil surface heat flux and soil surface temperature on soil surface energy balance closure. Journal of Geophysical Research, 115, D16112. http://dx.doi. org/10.1029/2009JD013 278

Oliveira, A.P.; Codato, G. \& Ruman, C.J. (2012). Relatório da $2^{a}$ campanha de medidas do projeto ETA. IAG/USP, 37p. Available from: <http://www.iag.usp.br/meteo/labmicro/publicacoes/TechnicalReports/index.html>

Wyngaard, J.C., (2010). Turbulence in the Atmosphere. Cambridge University Press.Cambridge, 393 p. 